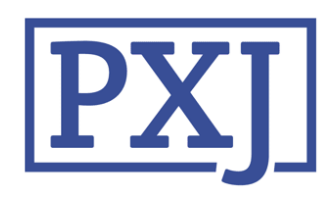

Patient Experience Journal

\title{
Applying experience-based co-design with vulnerable populations: Lessons from a systematic review of methods to involve patients, families and service providers in child and youth mental health service improvement
}

\author{
Alison Mulvale \\ OCAD University \\ Ashleigh Miatello \\ McMaster University \\ Christina Hackett \\ McMaster University \\ Gillian Mulvale \\ McMaster University
}

Follow this and additional works at: https://pxjournal.org/journal

Part of the Art and Design Commons, Health Policy Commons, Health Services Administration Commons, Health Services Research Commons, and the Mental and Social Health Commons

\section{Recommended Citation}

Mulvale A, Miatello A, Hackett C, Mulvale G. Applying experience-based co-design with vulnerable populations: Lessons from a systematic review of methods to involve patients, families and service providers in child and youth mental health service improvement. Patient Experience Journal. 2016; 3(1):117-129. doi: 10.35680/2372-0247.1104.

This Article is brought to you for free and open access by Patient Experience Journal. It has been accepted for inclusion in Patient Experience Journal by an authorized editor of Patient Experience Journal. 


\section{Applying experience-based co-design with vulnerable populations: Lessons from a systematic review of methods to involve patients, families and service providers in child and youth mental health service improvement}

\section{Cover Page Footnote}

This research is being funded through an Ontario Early Researcher Award. Sincere thanks to the Ontario Ministry of Research and Innovation. The views expressed in the systematic literature review are the views of the authors and should not be taken to represent the views of the Government of Ontario. Additional funding support provided by the DeGroote School of Business at McMaster University is greatly acknowledged. 
Applying experience-based co-design with vulnerable populations: Lessons from a systematic review of methods to involve patients, families and service providers in child and youth mental health service improvement

Alison Mulvale, BSc, OCAD University, alison.mulvale@gmail.com

Ashleigh Miatello, MA,McMasterUniversity,miatelam@momaster.ca

Christina Hackett, MA,MSc,McMasterUniversity, hacketc@mcmaster.ca

Gillian Mulvale,PhD,MA, McMaster University,Mulvale@momaster.ca

\begin{abstract}
The objective was to identify methods used to involve patients, family and service providers in child and youth mental health service improvement research. We analyzed the alignment of methods used with Experience-Based Co-Design (EBCD) methodology, and how power imbalances among participants were addressed. A systematic review of the English-language peer review literature since 2004 was carried out. The EMBASE, Scholar's Portal, PubMed, Web of Science databases and the Ontario College of Art and Design University libraries were searched electronically for variations of 'child', 'mental health', 'experience-based co-design', 'participatory research' and 'health care services'. Textual data was systematically extracted and analyzed. The electronic search identified 1468 articles; 13 remained following full text review and reference checking. Many participatory research studies in child and youth mental health were consistent with core elements of the EBCD methodology, but few focused on experiences and incorporated the perspectives of all participants throughout the research process. Story telling and visual media, employing youth as researcher partners, establishing equal status among participants, offering counseling support, paying particular attention to confidentiality, scheduling frequent breaks, and having skilled interviewers and facilitators were suggested methods to address power imbalances for this vulnerable population. Conclusion-The existing child and youth mental health participatory research literature aligns considerably with many elements of EBCD methodology and suggests diverse approaches to address power imbalances. More systematic application of the full range of elements will help to achieve patient centeredness and recovery in mental health and for other vulnerable populations.
\end{abstract}

\title{
Keywords
}

Child and youth, experience-based co-design, participatory research, mental health, person-centeredness, patient \& family engagement

\section{Note}

This research is being funded through an Ontario Early Researcher Award. Sincere thanks to the Ontario Ministry of Research and Innovation.. Additional funding support provided by the DeGroote School of Business at McMaster University is gratefully acknowledged. The views expressed in the systematic literature review are the views of the authors and should not be taken to represent the views of the Government of Ontario

\section{Introduction}

One of tenets of patient-centered care is capturing patient experience to inform system redesign. ${ }^{1}$ Experience-based co-design (EBCD) is a promising interdisciplinary methodology that is being increasingly used in health systems and service enhancement. ${ }^{2-4}$ In EBCD, patients work collaboratively with designers, family members and staff to improve service systems by translating the experiences of these groups into tangible service redesign. ${ }^{5}$ This approach may be beneficial in mental health service improvement, which in many jurisdictions ${ }^{6-12}$ has been rooted in health promotion ${ }^{13-16}$ and recovery principles ${ }^{10,17-}$
20 that call for integral involvement of consumers and families in system design and evaluation. ${ }^{20} \mathrm{~A}$ high priority in many jurisdictions is to improve child and youth mental health (CYMH) systems because of the significant and often continuing burden faced by youth transitioning into adulthood, and the risk of youth falling through the cracks in fragmented delivery systems. ${ }^{39-42}$ Children and youth with mental health issues represent a doubly vulnerable population; first because of their age, ${ }^{21}$ and second because of the powerful impact of stigma, ${ }^{22,23}$ which may silence or devalue the voices of people with mental illness as well as their family members when sharing their experiences. ${ }^{24-29}$ Little is known about how effective EBCD is in practice at

Patient Experience Journal, Volume 3, Issue 1 - Spring 2016

(C) The Author(s), 2016. Published in association with The Beryl Institute and Patient Experience Institute

Downloaded from www.pxjournal.org 
addressing the additional challenges that exist when including the experiences and perspectives of such vulnerable populations in service improvement.

The EBCD methodology in health care research arose from prior collaborative processes for users in health service and system improvement ${ }^{4}$ in the participatory research (PR) tradition, ${ }^{21,30-34}$ including participatory action research (PAR) and community-based participation research (CBPR). The PR tradition shifts the paradigm of 'research on' to 'research with'. 30,31,33,34 PR methodologies have been used to engage healthcare staff, 34 and more recently, users ${ }^{33,35}$ in assessing, intervening, implementing and evaluating service structure and flow. Core values include translating knowledge into action, social and environmental justice, and self-determination ${ }^{31}$ to subvert historical power imbalances between 'researcher' and 'subjects.' PR is often used in research to address health disparities for vulnerable populations and in populations traditionally oppressed and discriminated against in harmful research practices. ${ }^{30,34,36,37}$

The emphasis on experiences is what sets the EBCD methodology apart from most PR studies. EBCD also differs from traditional health services research, which typically focuses on quality and health outcomes, often using top-down approaches for organizational change. 4,34 EBCD recognizes the importance of safety and functionality as two components of good design, but also prioritizes usability (Adapted from Berkun (2004)), which rarely receives attention in health services research. ${ }^{38}$ The goal of an EBCD study is to improve the health service user's overall experience, by first identifying key 'touch points' along the patient journey where experiences evoke a strong emotional response for better or worse, and then enabling patients, family members and service providers to collaboratively redesign experiences at these touch points to improve local services and to derive design principles that can be applied more broadly.,3,4

The objective of this paper is to explore the participatory research literature pertaining to the improvement of child and youth mental health systems and services through the lens of the EBCD methodology. We outline important considerations for applying EBCD methods to drive system reform based on a systematic review of how these methods have been applied in the area of CYMH services that may be informative for other vulnerable populations. The findings contribute to a growing body of literature on EBCD and will be particularly useful for those interested in applying EBCD in domains where concerns about power imbalance among participants are particularly high.

\section{Methods}

\section{Search of Electronic Databases}

A systematic review of the peer review literature from 2004 to 2015 was carried out to identify studies that have used EBCD or other PR methods to improve CYMH services. We report the findings using the Preferred Reporting Items for Systematic reviews and Meta-Analyses (PRISMA) 43 as a guide. Keyword searches were conducted on the following electronic medical and health servicesrelated databases: EMBASE, Journals at Scholar's Portal, PubMed, and Web of Science. An additional search for design-related literature was carried out at the Ontario College of Art and Design University's library. Search strings combined the following terms as well as relevant variations of each term: 'child', 'mental health', 'experience-based co-design', 'participatory research,' and 'health care services'. Variations of experience-based codesign included research methods that also engage users and utilize their experiences to inform health care service design such as 'experience-based design' and 'participatory action research'. For the purposes of this literature review, 'mental health' includes mental disease, mental disorder, mental illness, intellectual disabilities, as well as mood and eating disorders. Search strings were adjusted as necessary for each database. References of included papers were checked to identify additional articles.

\section{Study Selection and Eligibility Criteria}

Studies were selected using the following inclusion criteria: 1) published in 2004 or later; 2) English language; 3) CYMH services; 4) participatory research or experiencebased design or experience-based co-design. Studies were excluded based on the following criteria: 1) studies not related to $\mathrm{CYMH}$; 2) literature reviews 3)

theses/dissertations, brief articles, conference proceedings, commentaries, letters, medical newsletters, book reviews. The lead author conducted title, abstract and full text reviews and the research team members screened a selection of the articles during each phase and met to discuss discrepancies until consensus was reached. The search resulted in 1468 articles of which 13 met the eligibility criteria. All included articles were appraised for methodological rigor using Hawker and colleagues' criteria $^{44}$ for scoring qualitative research. Two authors independently appraised each article and subsequently met to discuss any discrepancies. There was at least $90 \%$ agreement on the overall scores for each paper.

\section{Data Screening and Extraction}

Textual data were systematically extracted from the articles using a data extraction spreadsheet with content as reflected in Table 1. A second stage of data extraction was carried out in the development of analytic themes that focused on how well the studies aligned with the EBCD methodology discussed below and how they addressed 
power differentials for children and youth with mental disorders and their family members.

\section{Data Analysis}

The studies were first reviewed to understand the study aim and setting, types of participants engaged in the mental health care service redesign process and to gain an overview of the methods used. We then compared the methods used in the identified articles with those suggested by Bate and Robert at the various stages of the EBCD methodology ${ }^{4}$ (diagnostic, intervention, implementation and evaluation). Although most of the identified studies did not explicitly describe their activities using EBCD language, the research team was in agreement about how the activities corresponded to identifying positive and negative experiences (diagnostic stage), developing solutions to identified problems (intervention stage), as well as implementing and evaluating the developed solutions. Key themes pertaining to methods to address power differentials among children and youth, family members and service providers as study participants were also extracted from each article and discussed by members of the research team to capture recommendations for future EBCD studies.

We next examined the extent to which the various studies achieved the five elements that characterize EBCD studies as distinct from traditional participatory research. We assessed and applied a score ranging from 0 to 3 (not at all, minimally, somewhat, and fully) to represent the extent to which each element of the EBCD methodology was met. Two members of the research team independently scored the methods used in the articles on each dimension and then discussed any discrepancies until agreement was reached.

\section{A Methodological Framework to Explore EBCD Methods}

With insights gained from understanding the experiences of service users, family members and service providers; EBCD seeks to redesign health service experiences such that user experience is given a platform that can be meaningful in system change and adaptation. ${ }^{4}$ Like PR, key elements of EBCD include participation and action to change an experience of a phenomenon, often among vulnerable groups. Despite the similarities between EBCD and PR, EBCD studies distinctly:

1. Involve users and professionals throughout the design process as co-designers of services.

2. Focus on service experiences as a whole rather than user satisfaction.

3. Focus on designing improved experiences, not merely processes, systems or the built environment, by identifying the touch points, or the polarizing moments when experiences are powerfully shaped.

4. Use analytic frameworks to understand user experiences within their context.

5. Focus on improving the interface between the user and service by interpreting experiences.

(Adapted from Bate \& Robert 2007) ${ }^{4}$

Bate and Robert divide the EBCD methodology into four stages (Figure 1). Some methods of each stage align with other traditional health service research traditions, but also feature a number of approaches more typically associated with the design sciences. EBCD studies combine one or more of these approaches for each stage with the engagement of service users, providers and families who together design improved experiences. ${ }^{4}$ Each method has its own advantages and disadvantages and can be used in isolation or in conjunction with other methods.

\section{Diagnostic Methods}

EBCD methods feature photo-journaling, videotaping and other forms of visual media that are extensively used in the design sciences to elicit experience data, in addition to more traditional individual interviews, focus groups and ethnographic observation. Photo-journaling by stakeholders can be an important data source, and the photos can also be used to keep stakeholders as well as the physical environment in mind throughout the design process. Video storytelling by participants enables stakeholders to control the direction of the narrative and helps to humanize the accounts. Replaying videotapes during the co-design stage can be highly effective in bringing participants with different perspectives together to collaborate in addressing problematic experiences.

\section{Intervention Methods}

A key milestone in any EBCD study is the co-design event where multiple stakeholders work together to develop one or more interventions to address negative touch points in the particular service and to derive design principles that can apply more generally. The EBCD methodology draws on a number of methods from the design sciences that anticipate and help to overcome obstacles to more vulnerable service users' voices being heard. Some methods focus on priority setting and visualising the experience in a sequential manner. These include cognitive walkthroughs that imagine the experience of the proposed design solution, card sorting to organize and prioritize touch points, experience mapping the states and transitions of an experience, and storyboarding to visually represent key moments of the experience. Other methods focus on eliciting feelings about experiences or developing a common language to overcome barriers in understanding. The 'path of expression' method begins with users visualizing their service experiences, expressing 


\section{Figure 1: Experience-Based Co-Design Stages and Methods}
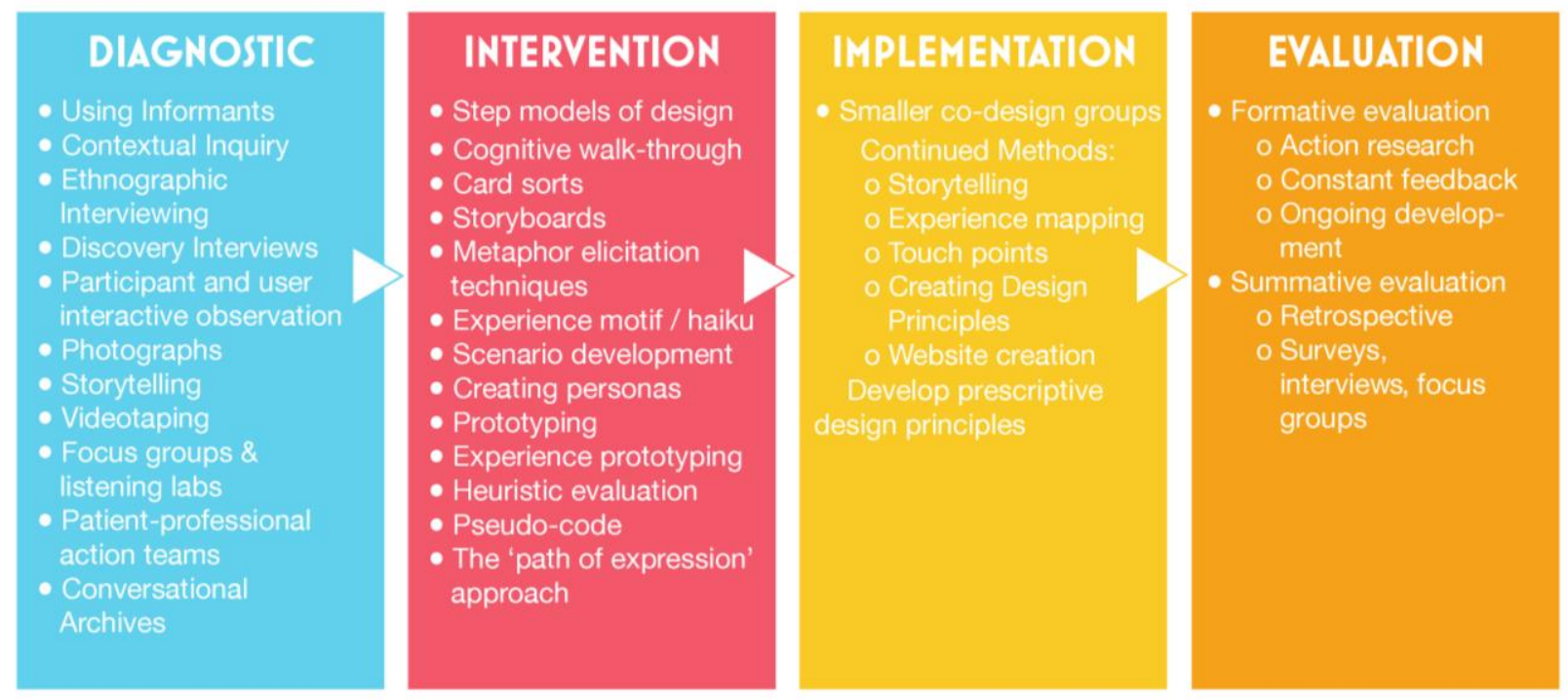

Note: Though Figure 1 displays methods in a linear sequence, EBCD methods can be used flexibly/concurrently.

these to the group, imagining an ideal experience and then creating solutions from the idealized experiences.

\section{Implementation Methods:}

The goal of this stage is to further develop and implement design principles that will improve experiences at the touch points. Unlike the diagnostic and intervention methods, less detail is provided by Bate and Robert about implementation strategies. ${ }^{4}$ This is analogous to many research paradigms aimed at system change, in which implementation science is under-developed, and the feasibility of putting findings into action faces barriers external to the research process. ${ }^{45}$ Many of the methods described above, such as prototyping may be used with a focus on how to implement interventions and design principles, although other implementation strategies may be required.

\section{Evaluation Methods}

The aim at this stage is to make improvements throughout the design process. Formative evaluations enable ongoing improvement during the design and implementation of the intervention. ${ }^{4}$ This is facilitated by the action research approach, where feedback between researchers and participants is ongoing throughout the design process. Summative evaluations use methods such as retrospective surveys, interviews and focus groups to assess the extent to which co-designed interventions are implemented and resolve intended issues.

\section{Results}

The initial search yielded 1468 articles from the 5 databases (Figure 2). From those articles, 244 duplicates were removed, leaving 1224 articles. Following title review 89 articles remained, of which 26 remained following abstract review. The remaining articles then underwent a full text review that left 12 articles. One additional article was added after reviewing the selected articles' bibliographies.

\section{Overview}

Table 1 provides an overview of the existing studies in the current literature in terms of their aim, location, participant types, and types of methods used according to the EBCD methodological framework as well as their Quality Assessment Scores (QAS) out of a maximum of 400 points. Most studies scored in the fair to good range. Only one modified EBCD study was identified in the literature. ${ }^{5}$ The majority of studies frame themselves as some form of PR. ${ }^{46-55}$ It should be noted that in some cases, different stages or dimensions of the same larger research project where published in separate articles by different authors. For example, the articles by Read-Searl, Happell, and Moxham ${ }^{50-52}$ pertain to the same research project, as do the two articles by Day. ${ }^{56,57}$

\section{Elements Consistent with EBCD}

In reviewing the literature, we examined the extent to which the identified studies aligned with the EBCD elements: (i) inclusion of the full range of stakeholders, (ii) involvement of users throughout the study, (iii) inclusion of the whole service, (iv) focus on user experience and (v) 
Figure 2: Systematic Literature Review Search Results

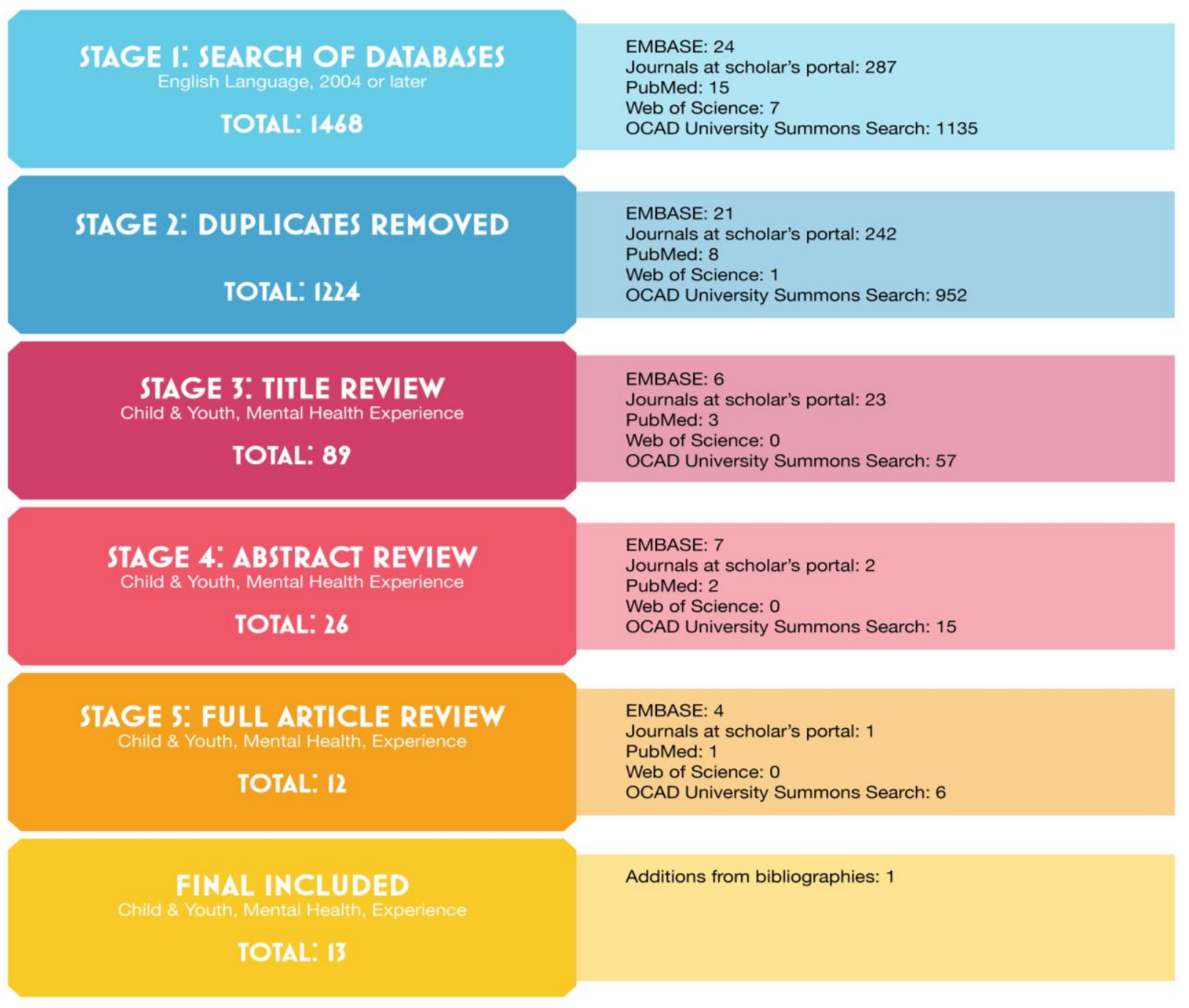

consideration of the implications for the interface between users and service providers; as well as the extent to which studies included multiple stakeholder voices, and included the four stages of the EBCD process (Figure 3). As can be seen from Figure 3, the studies varied in the extent to which these elements were met.

The larger map shows the extent to which studies collectively aligned with each element of the EBCD methodology by layering individual study's maps on top of one another (Figure 3). The opacity of the figure is greater where multiple studies met elements to the same extent, such as in the centre of the figure. Here all of the studies met all the elements at least minimally. In contrast, the figure is more transparent when studies did not align. Studies whose mapped layer extends to the vertices of hexagon align fully with that EBCD element.
Unsurprisingly, the only study to fully incorporate all of these elements was the study that adopted a modified EBCD approach. ${ }^{5}$ What is more surprising is the extent to which several of the other PR studies also included elements consistent with the EBCD methodology. For example, all of the studies sought to improve the interface between users and service providers. $5,46-57$ Additionally, eight studies $5,46-48,50-54,56,57$ looked at the whole service rather than specific aspects of it, and seven studies ${ }^{5,49-57}$ involved all stages of the EBCD process. Only five of the studies, 5 ,46-48,50-52 looked directly at improving service experience, as two studies developed tools to assist service improvement ${ }^{53,56,57}$ and three other studies focused on examining service delivery, which indirectly provided insights into experience. ${ }^{49,54,55}$ Only three studies to date $5,46,55$ engaged all stakeholder types. Only four studies $5,46,48,53$ engaged their included stakeholders throughout the entire design process. 
(Authors note: We were unable to assess the extent to which the studies addressed the fourth element of an EBCD study (use of analytic frameworks to understand the user in their context) based on information provided in the studies, so we have excluded it from the analysis. In addition (v) also includes Reid-Searl 2009 and Moxham 2010)

\section{Methods Used in the Studies}

\section{Diagnostic Methods}

Methods aligning with the diagnostic EBCD phase were used in all of the studies, although they did not use the EBCD language to describe this stage. Four studies ${ }^{54,57}$ used individual interviews and ten used focus groups under various names ${ }^{5,46,47,49-56}$ (e.g. feedback groups, workshops) to understand experiences of stakeholders. Generally the authors found that interviews and focus groups offer a safe space for youth to share experiences, which was especially important when participants were critical of service providers. ${ }^{48,57}$ Focus groups enabled researchers to gain additional insight compared to individual interviews. ${ }^{57}$ In two studies, concerns about power differentials within focus groups were raised; in one study the groups contained only one participant type ${ }^{48}$, and in the other the groups were mixed. ${ }^{49}$ Facilitators were helpful in ensuring that dominant individuals did not skew the discussion and in allowing quieter participants to share

\section{Figure 3: Alignment of Studies with EBCD Methodology}

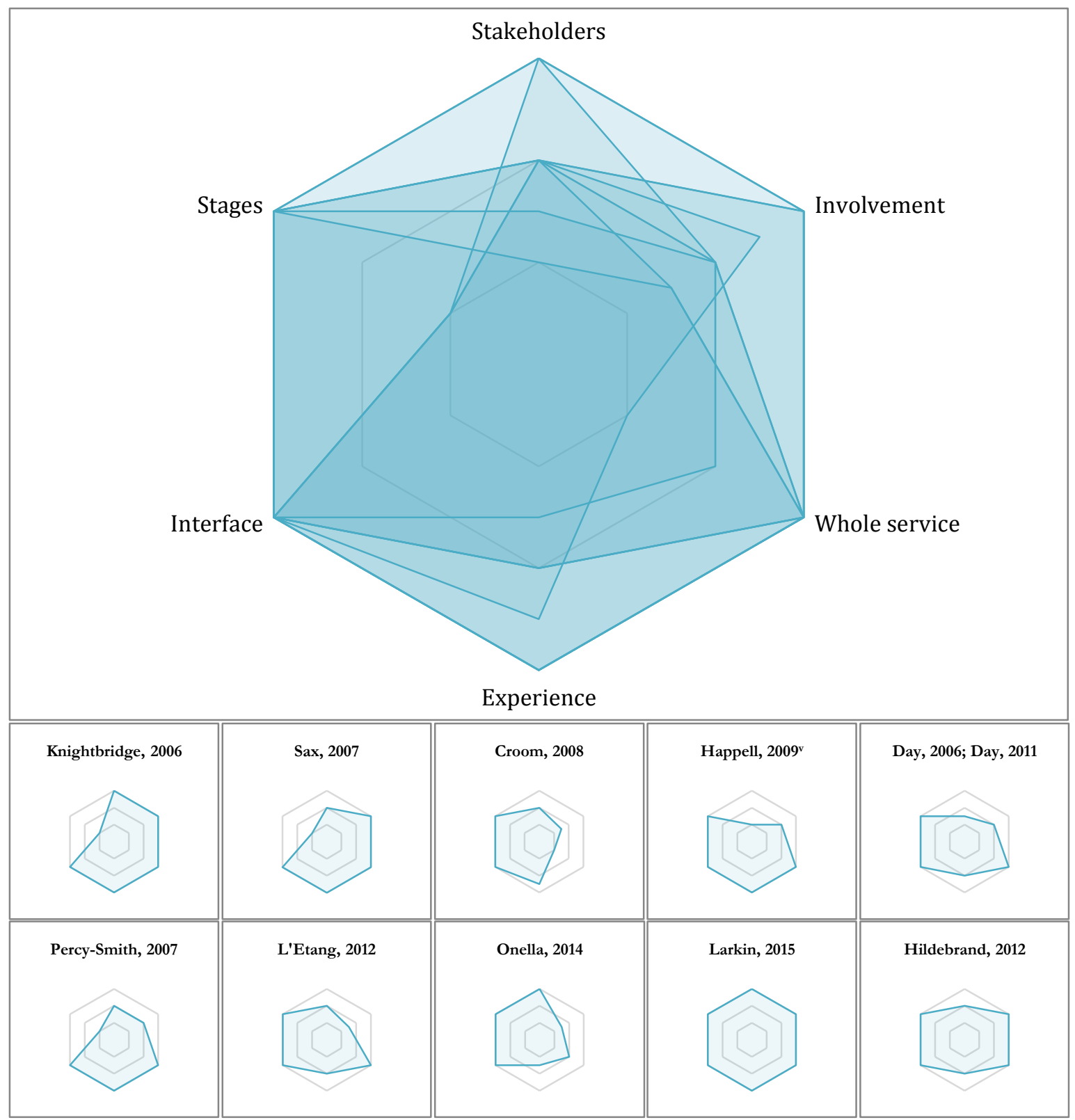


ideas. ${ }^{46}$ Offering participants the option of an individual interview increased the comfort of some participants when providing their input in one study. ${ }^{51}$ Some authors suggested including peer counselors to encourage the discussion of taboo subjects, as well as to elicit a more holistic understanding of experiences. ${ }^{54}$ Parents were reported as feeling empowered by offering their insights, and a shift in the power balance between parents and service providers was reported as iterative interviews and focus groups progressed. ${ }^{48}$

Three studies used visual media during the diagnostic stage. The modified EBCD study identified touch points based on earlier qualitative interviews and used subsequent videotapes of interviews in the intervention stage. ${ }^{5}$ Another study used videos of interviews with family members in subsequent meetings with service providers. ${ }^{48}$ In both studies, sensitive material and personal details, 5,48 were edited out to ensure that video clips would set a constructive tone for discussions and not create tension between the groups. Participants viewed the clips in advance of group events to make sure they were comfortable with the contents. ${ }^{5}$ The use of video was described as a powerful tool to relay priorities at co-design sessions ${ }^{5}$ and to illustrate shifts in power relationships between stakeholder groups over iterative sessions. ${ }^{48}$ One article reported that having youth leaders create and display posters of their experiences enabled discussion of novel and complex health issues that were not being addressed by current policy. ${ }^{47}$ Posters were also described as an inclusive and evocative medium for young people to effectively share health issues. ${ }^{47}$

\section{Intervention Methods}

Traditional interviews and focus groups, ${ }^{48-56}$ as well as design methods such as card sorting for concept mapping ${ }^{46}$ and visual media were used to ensure youth voices were heard in developing the interventions. ${ }^{47}$ In the modified EBCD study, facilitated mixed focus groups were assigned one touch point each to address during the intervention stage at a large co-design event. ${ }^{5}$ One study employed youth service users as research assistants in developing a toolkit to evaluate youth mental health service experience. ${ }^{53}$ Another study empowered youth leaders to create visual media to express their vision of healthy futures at a conference attended by professionals. ${ }^{47}$ Although time consuming, this approach was effective in encouraging action on youth-led proposals. ${ }^{47,53}$

\section{Implementation Methods}

Seven articles discussed studies that progressed to the implementation stage. ${ }^{49,53-56}$ One article described the establishment of a steering committee comprised of volunteers from the co-design event to support implementation of identified improvements. ${ }^{5}$ Another study that was exclusively conducted by and with service providers, was able to directly implement their proposed intervention. ${ }^{52}$ Another study found that the lack of inclusion of youth in the intervention stage presented problems during implementation, which led to refinement of the intervention. ${ }^{54}$ Another article suggested that involving peer-counsellors when piloting interventions could be a way to empower youth to voice their thoughts and concerns. ${ }^{54}$

\section{Evaluation Methods}

Seven articles described activities that aligned with the evaluation phase of the EBCD methodology. Five studies used formative evaluation to pilot and incorporate stakeholder feedback prior to full implementation. ${ }^{49,53-56}$ Two other articles used focus groups and audits as summative evaluation methods. ${ }^{5,52}$. The focus groups led to increased service provider self-awareness about strengths and areas for self-improvement. ${ }^{52}$ Audits following a co-design event showed that one third of interventions had been implemented at nine months, but that at 12 months, systemic difficulties hindered full implementation due to insufficient organizational dedication to the implementation stage. ${ }^{5}$ Similar problems were described in another article where implementation was not within the mandate of the research team. ${ }^{47}$

\section{Discussion}

The EBCD methodology holds particular appeal to empower patients to contribute to the redesign of health services to improve the patient experience, particularly for vulnerable populations whose voices are often not considered, such as children and youth with mental disorders and their family members. Our objective in this review was to identify existing studies that aligned with the intent of the EBCD methodology, in order to assess the extent to which EBCD elements have been applied, and to understand how issues of power imbalance have been addressed. We were limited in the number of EBCD studies relevant for this review; however, similar PR approaches that have been more widely used in the area of CYMH suggest key considerations for future EBCD studies to capture patient experiences of vulnerable populations.

Elements of the EBCD methodology were evident among all articles, although the studies they described placed varied emphasis on the different elements of the methodology. Most of the studies moved beyond the diagnostic and intervention to the implementation and evaluation stages, and it is possible that subsequent implementation and evaluation work has not yet been published for other studies. The most common EBCD element present in the studies was consideration given to improving the interface between service user and provider, which was present in all studies. There was strong support for the use of videos in several studies at the diagnostic stage to help set the stage for a productive dialogue, 5,47,48 
with importance placed by the authors on editing out personal details and controversial clips. ${ }^{5}$ At the intervention stage, methods consistent with EBCD mostly involved use of visual media, although card sorting was also used in one study ${ }^{46}$ and use of professional facilitators during workshops or other large co-design events in another. ${ }^{5}$ Limited detail was provided at the implementation and evaluation stages.

The articles reviewed described novel ways to redistribute power across participant types, such as by employing youth as research assistants ${ }^{30}$ or empowering youth to share their experiences through use of visual media ${ }^{23}$ at workshops and events involving service providers. Authors also suggested the importance of having a number of methods to draw on to give equal opportunity to the various participant types when conducting group work between care providers and recipients. ${ }^{57}$ More generally, being clear about everyone's motivations for participating, using straightforward language, acknowledging and diffusing tensions as they arise, empowering youth and family members by legitimizing their opinions, acknowledging the diversity of participants and their experiences, and managing expectations of the potential for change were recommended. 5

It is also essential when working with vulnerable populations such as children with mental health issues and their families to attend to issues of stigma and distress, which makes them vulnerable when sharing experiences. ${ }^{5}$ The identified articles for the most part were fairly silent on these points, however one article ${ }^{5}$ emphasized that by creating equal status among participants at a co-design event, positive intergroup attitudes can be created, consistent with the literature on contact among stigmatized groups. ${ }^{58,59}$ Other factors that potentially could assist with these issues include having a skilled facilitator, ${ }^{5,46,52}$ offering counselling support, ${ }^{5}$ scheduling frequent breaks, ${ }^{5}$ and paying particular attention to confidentiality. $5,47,48$

Most of the studies appeared to be at least partially successful in meeting their stated objectives with regard to including the voices of youth and family members and addressing power imbalances. Diagnostic and intervention methods were satisfying to participants. Of the studies that did move to implementation stages, most experienced some degree of success. 5,48,52,56 There was also support for the broader notion that research can be strategically used to facilitate action, implementation ${ }^{55}$ and evaluation. ${ }^{52}$ The programme of research by Happell, Reid-Searl and Moxham, appeared to successfully integrate findings sequentially from each phase. Perhaps this is because the PAR approach was initiated by service providers aiming to improve their own practice rather than by an external group, which enabled them to implement and evaluate this reflexively. The Day program of research also appeared to successfully integrate all phases, again with service providers identifying the need for change and initiating and executing solution-focused research. 5,54

However, in a few cases ${ }^{47,50}$ little or no action followed the research. Even with the attention paid to participant involvement, it is disappointing that more action is not seen at the implementation and evaluation stages in these studies. Nonetheless, even when change was not fully implemented, several studies point to intermediate impacts from sharing complex ideas between clients and providers, ${ }^{49,57}$ engaging youth in a process of learning that can support change, ${ }^{47}$ helping family members to find their voice, ${ }^{48}$ and ensuring that perspectives of youth assist in improving interventions. ${ }^{54,56}$

In some cases, there was not enough detail to assess methods, which posed a challenge to our analysis. For example, during the diagnostic stage, details on the types of interviews used and what activities occurred during focus groups was lacking, and prohibited comparison with the detailed methods suggested in the EBCD methodological framework. It is also important to recognize that most studies did not set out to adopt an EBCD approach; however all research team members readily agreed about the extent to which the various methods described in each study corresponded to the stages aligned in the EBCD methodological framework.

Despite the successes described in the identified studies, it is apparent that opportunities exist to more fully align with EBCD elements in studies geared to using patient, family member and service provider experiences for child and youth mental health system redesign. The use of storytelling techniques at the diagnostic stage, cognitive walkthroughs, storyboards and the development of scenarios and personas at the intervention stage, and the use of co-design or similar events involving all stakeholders may be key strategies to engage vulnerable populations in future studies. The establishment of ongoing working groups and continued formative and summative evaluation may also help to sustain momentum by all participants beyond the diagnostic and intervention stages. Key lessons are that it is important to have buy-in for implementation from the service from the start, and to plan for continued involvement of the research team through the evaluation phase to achieve the promises associated with the EBCD methodology.

At the same time, some realism is required with respect to anticipated systems reform on the basis of an EBCD research study. For example, while change may result at the local level based on an EBCD study, more widespread implementation in other organizations will depend on organization culture at the meso level and policy considerations (e.g. with respect to funding, remuneration, professional scopes of practice) at the macro level. ${ }^{60}$ Setting realistic expectations is important to avoid 
disappointing and disenfranchising EBCD participants, particularly when they are members of vulnerable groups. For example, the authors of one study indicated that the targeted model developed was unlikely to create systemic change unless it were part of a model to improve integration more broadly. ${ }^{46}$

\section{Conclusion}

The EBCD method holds considerable promise as an inclusive way to design better experiences. There is considerable overlap with PR approaches, but through explicit focus on patient experiences, the EBCD methodology may offer particular advantages in operationalizing patient-centred care consistent with a recovery orientation for child and youth mental health services. The results of this study suggest methods that can be systematically applied to advance through the diagnostic and intervention stages of the EBCD methodology, though more evidence is needed to better assess its promise in engaging vulnerable populations, particularly when moving through the implementation and evaluation stages. Future studies should focus directly on experiences as well as on engaging all stakeholder types throughout the design process.

\section{References}

1. Harkness J. Patient involvement: a vital principle for patient-centred health care. World Hosp Health Serv. 2005;41 (2):12-16.

2. Donetto S, Tsianakas V, Robert G. Using Experiencebased Co-design (EBCD) to improve the quality of healthcare: mapping where we are now and establishing future directions. National Nursing Research Unit;2014.

3. Bate P, Robert G. Experience-based design: from redesigning the system around the patient to codesigning services with the patient. Qual Saf Health Care. 2006;15(5):307-310.

4. Bate P, Robert GB. Bringing user experience to bealthcare improvement: the concepts, methods and practices of experiencebased design. Oxford: Radcliffe publishing; 2007.

5. Larkin M, Boden ZV, Newton E. On the brink of genuinely collaborative care: experience-based codesign in mental health. Qual Health Res. 2015.

6. Deegan P. Recovery and empowerment for people with psychiatric disabilities. Social Work in Health Care. 1997;25(3):11-24.

7. Jacobson N, Curtis, L. Recovery as policy in mental health services: strategies emerging from the States. Psychiatr Rehabil J. 2000;Spring.

8. New Zealand Mental Health Commission. Recovery competencies for New Zealand mental health workers. Wellington, New Zealand: Mental Health Commission;2001.
9. Provencher H, Keyes C. Complete mental health recovery: bridging mental illness with positive mental health. J Public Ment Health. 2011;10(1):57-69.

10. Shepherd G, Boardman J, Slade M. Making recovery a reality. London, U.K.: Sainsbury Centre for Mental Health;2008.

11. Mental Health Commission of Canada. Toward recovery and well-being, a framework for a mental health strategy for Canada. Calgary, AB: MHCC;2009.

12. Mental Health Commission of Canada. Changing directions changing lives, the Mental Health Strategy for Canada. Calgary, AB: MHCC;2012.

13. Pan-Canadian Committee for Mental Health Promotion and Mental Illness Prevention. Towards flourishing for all: national mental health promotion and mental illness prevention policy for Canadians. 2009;

http://www.utoronto.ca/chp/mentalhealthpdffinal/ Towards Flourishing for All Policy Recommendations Final April.pdf. Accessed April 17, 2014.

14. Mental Health Commission of Canada. Evergreen: $A$ child and youth mental health framework for Canada. Mental Health Commission of Canada;2010.

15. Mulvale G, Bartram M. No more "us" and "them": integrating recovery and well-being into a conceptual model for mental health policy. Can J Commun Ment Health. 2015;In-Press.

16. World Health Organization. Promoting mental health: Concepts, emerging evidence, practice. Geneva: Author;2005.

17. Slade M. 100 ways to support recovery: a guide for mental health professionals. Rethink recovery series (vol 1) 2009; http://www.mentalhealthrecovery.com/ recoveryresources/documents/100_ways_to_support _recovery1.pdf. Accessed April 17, 2014.

18. Slade M, Adams N, O’Hagan M. Recovery: past progress and future challenges. Int Rev Psychiatr. 2012;24(1):1-4.

19. Slade M, Amering M, Oades L. Recovery: an international perspective. Epidemiologia e Psichiatria Sociale. 2008;17(2).

20. Anthony W. Recovery from mental illness: the guiding vision of the mental health service system in the 1990s. Psychiatr Rehabil J. 1993;16(11-23).

21. Bombard Yea. Eliciting ethical and social values in health technology assessment: a participatory approach. Soc Sci Med (1982). 2011;73(1):135-144.

22. Stuart H, Arboleda-Florez J, Sartorius N. Paradigms Lost: Fighting Stigma and the Lessons Learned. USA: Oxford University Press; 2012.

23. Rüsch N. Angemeyer, M., Corrigan, P. Mental illness stigma: concepts, consequences, and initiatives to reduce stigma. Eur Psychiatry. 2005;20(8):529-539.

24. National Mental Health Consumer \& Carer Forum of Australia. The mental health consumer and carer identified workforce- a strategic approach to recovery. Canberra: NMHCCF;2010. 
25. Plachta-Elliott S, Delman J. Consumer-led evaluation teams: a peer-led approach to assessing consumer experiences with mental health services. Lawrence, MA: National Empowerment Center; 2009.

26. Dinos S, Stevens S, Serfaty M, Weich S, King M. Stigma: the feelings and experiences of 46 people with mental illness. Br J Psychiatry. 2004;184(2):176-181.

27. Deighton Jea. Measuring mental health and wellbeing outcomes for children and adolescents to inform practice and policy: a review of child self-report measures. Child and adolescent psychiatry and mental health. 2014;8:14.

28. Miller S,,Duncan, B. Paradigm lost: From modeldriven to client-directed, outcome-informed clinical work. JSyst Ther. 2000;19(1):20-34.

29. Trask EV, Garland, AF. Are children improving? Results from outcome measurement in a large mental health system. Adm Policy Ment Health. 2012;39(3):210220.

30. Buchanan DR, Miller, F.G. \& Wallerstein, N. Ethical issues in community-based participatory research: balancing rigorous research with community participation in community intervention studies. Prog Community Health Partnersh. 2007;1(2):153-160.

31. Cargo MM, S.L. The value and challenges of participatory research: strengthening its practice. Annual review of public bealth. 2008;29:325-350.

32. Cousins JB,Earl LM. The Case for Participatory Evaluation. Educ eval policy an. 1992;14(4):397-418.

33. Couzos, S. "We are not just participants--we are in charge": the NACCHO ear trial and the process for Aboriginal community-controlled health research.Ethnic Health. 2005;10(2):91-111.

34. Wallerstein NB, Duran,B. Using Community-Based Participatory Research to Address Health Disparities. Health Promot Pract. 2006;7(3):312-323.

35. Lennie J. An evaluation capacity-building process for sustainable community IT initiatives: empowering and disempowering impacts. Evaluation. 2005;11(4):390414.

36. Smith L, Chambers, .D-A, Bratini L. When oppression is the pathogen: the participatory development of socially just mental health practice. American J Oorthopsychiatr. 2009;79:159-168.

37. Zavala M. What do we mean by decolonizing research strategies? Lessons from decolonizing indigenous research projects in New Zealand and Latin America. Decolonization: Indigeneity, Education \& Society. 2013;2(1):55-71.

38. Bate P, Robert G. Toward more user-centric OD: lessons from the field of experience-based design and a case study. J Appl Behavl Sci. 2007;43(1):41-63.

39. Davidson S, Cappelli M. We've got growing up to do: transitioning from child and adolescent mental health services to adult mental health services. Ottawa: Ontario Centre of Excellence for Child and Youth Mental Health;2011.
40. McGorry P. The specialist youth mental health model: strengthening the weakest link in the public mental health system. Med J Aust. 2007;187(7):S53-56.

41. Singh S. Transition of care from child to adult mental health services: the great divide. Curr Opin Psychiatry. 2009;22(4):386-390.

42. Singh S, Evans N, Sireling L, et al. Mind the gap: the interface between child and adult mental health services. Psychiatr Bull. 2005;29(8):292-294.

43. Mohler D, Shamseer L, Clarke M, et al. Preferred reporting items for systematic review and metaanalysis protocols (PRISMA-P) 2015 statement. Syst Rev. 2015;4(1):1-9.

44. Hawker S, Payne S, Kerr C, Hardey M, Powell J. Appraising the evidence: reviewing disparate data systematically. Qual Health Res. 2002;12(9):1284-1299.

45. Greenhalgh T, Robert G, Macfarlane F, Bate P, Kyriakidou O. Diffusion of innovations in service organizations: systematic review and recommendations. Milbank Q. 2004;82(4):581-629.

46. Knightbridge SM, King R, Rolfe TJ. Using participatory action research in a community-based initiative addressing complex mental health needs. Aust N Z J Psychiat. 2006;40(4):325-332.

47. Percy-Smith B. 'You think you know? ... you have no idea': youth participation in health policy development. Health Educ Res. 2007;22(6):879-894.

48. Sax P. Finding common ground: parents speak out about family-centered practices. J Syst Ther. 2007;26(3):72-90.

49. Croom S, Procter S. Increasing systemic capacity to respond to child and adolescent mental health needs using reciprocal knowledge transfer with parents. Prim Health Care Res Dev. 2008;9(1):49-63.

50. Happell B, Moxham L, Reid-Searl K, et al. Promoting mental health care in a rural paediatric unit through participatory action research. Aust JRural Health. 2009;17(3):155-160.

51. Reid-Searl K, Dwyer T, Happell B, et al. Caring for children with complex emotional and psychological disorders: experiences of nurses in a rural paediatric unit. J Clin Nurs. 2009;18(24):3441-3449.

52. Moxham L, Dwyer T, Happell B, et al. Recognising our role: improved confidence of general nurses providing care to young people with a mental illness in a rural paediatric unit. J Clin Nurs. 2010;19(910):1434-1442.

53. Hildebrand J, Lobo R, Hallett J, Brown G, Maycock B. My-peer toolkit [1.0]: Developing an online resource for planning and evaluating peer-based youth programs. Youth Studies Australia. 2012;31(2):53-61.

54. L'Etang S, Theron L. A critical reflection on the participatory action process involved in the development of a cognitive-behavioural-based counselling intervention programme for youth living with HIV/AIDS in a rural South African town. Action Research. 2012;10(1):5-21. 
55. Onnela AM, Vuokila-Oikkonen P, Hurtig T, Ebeling H. Mental health promotion in comprehensive schools. J Psychiatr Ment Health Nurs. 2014;21(7):618627.

56. Day C, Michelson D, Hassan I. Child and adolescent service experience (ChASE): measuring service quality and therapeutic process. Br J Clin Psychol. 2011;50(4):452-464.

57. Day C. Children's key concerns: piloting a qualitative approach to understanding their experience of mental health care. Clin Child Psychol Psychiatry. 2006;11(1):139-155.

58. Pettigrew TF, \& Tropp, LR. A meta-analytic test of intergroup contact theory. J Pers Soc Psychol. 2006;90:751-783.

59. Schofield JW, Eurich-Fulcer R. When and how school desegregation improves intergroup relations. The Blackwell handbook of social psychology: intergroup processes Malden, MA: Blackwell; 2001:475-494.

60. Mulvale G, Bourgeault I. Finding the right mix: how do contextual factors affect collaborative mental health care in Ontario? Can Public Pol. 2007;XXXIII(S1):49-64. 
Table 1: Overview of the Methods Used in the Identified Studies

\begin{tabular}{|c|c|c|c|}
\hline Citation & Study Aim & Alignment with EBCD Methods & Notable Findings \\
\hline $\begin{array}{l}\text { Knightbridge, } \\
2006^{46} \\
\text { QAS: } 332.5\end{array}$ & $\begin{array}{l}\text { Examine complex } \\
\text { mental health needs } \\
\text { with youth, parents } \\
\text { and service providers } \\
\text { in Australia using } \\
\text { PAR. }\end{array}$ & $\begin{array}{l}\text { Diagnostic } \\
\text { - First set of mixed focus groups used } \\
\text { qualitative inquiry process. } \\
\text { Intervention } \\
\text { - Second set of focus groups clarified themes } \\
\text { using a Likert type survey and concept } \\
\text { mapping using card sorting. }\end{array}$ & $\begin{array}{l}\text { - Author states that this } \\
\text { model is unlikely to create } \\
\text { systemic change unless } \\
\text { embedded in a model that can } \\
\text { organize expansive efforts at } \\
\text { integration. }\end{array}$ \\
\hline $\begin{array}{l}\text { Percy-Smith, } \\
2007^{47} \\
\text { QAS: } 302.5\end{array}$ & $\begin{array}{l}\text { Involve young people } \\
\text { and service providers } \\
\text { in identifying health } \\
\text { issues in the UK using } \\
\text { Community Based } \\
\text { Action Research. }\end{array}$ & $\begin{array}{l}\text { Diagnostic } \\
\text { - } 11 \text { youth peer leaders conducted research } \\
\text { with peers using posters \& video. } \\
\text { Intervention } \\
\text { - Posters were presented at a large-scale event } \\
\text { that involved discussions, working with visual } \\
\text { media and a plenary discussion panel on } \\
\text { action items. }\end{array}$ & $\begin{array}{l}\text { - Engaging youth in } \\
\text { supporting change. } \\
\text { - Despite promises to act; one } \\
\text { year later there was no follow } \\
\text { up. Author states this reflects } \\
\text { professionals' response rather } \\
\text { than the research approach. }\end{array}$ \\
\hline $\begin{array}{l}\text { Sax, } 200748 \\
\text { QAS: } 345\end{array}$ & $\begin{array}{l}\text { Improve } \\
\text { communication with } \\
\text { parents of children } \\
\text { with mental health } \\
\text { difficulties in the US } \\
\text { using PAR and } \\
\text { Narrative } \\
\text { Practices. }\end{array}$ & $\begin{array}{l}\text { Diagnostic } \\
\text { - } 20 \text { narrative interviews with families and } \\
\text { service providers. Focus groups watched and } \\
\text { were interviewed about ideas sparked by } \\
\text { videos of interviews. Original interviewees } \\
\text { were interviewed about witness reflections } \\
\text { that stood out. } \\
\text { Intervention } \\
\text { - Focus groups discussed future actions. }\end{array}$ & $\begin{array}{l}\text { - Many parents found their } \\
\text { voice, and providers learned } \\
\text { how powerful their } \\
\text { involvement could be. The } \\
\text { process in itself was an } \\
\text { intervention where the } \\
\text { individuals involved } \\
\text { experienced changes in } \\
\text { attitudes and approaches. }\end{array}$ \\
\hline $\begin{array}{l}\text { Croom, } 2008^{49} \\
\text { QAS: } 297.5\end{array}$ & $\begin{array}{l}\text { Develop a framework } \\
\text { for knowledge } \\
\text { exchange with service } \\
\text { providers for youth } \\
\text { experiencing } \\
\text { behavourial } \\
\text { difficulties in the UK } \\
\text { using Action } \\
\text { Research. }\end{array}$ & $\begin{array}{l}\text { Diagnostic \& Intervention } \\
\text { - Nurses combined their tacit knowledge with } \\
\text { literature to develop a framework for } \\
\text { reciprocal knowledge transfer that can solve } \\
\text { parents' problems. } \\
\text { Implementation \& Evaluation } \\
\text { - Piloted this approach with parents who } \\
\text { identified critical incidents in groups around } \\
\text { CYMH experience and discussed how to } \\
\text { implement solutions and trialed in } \\
\text { communities. }\end{array}$ & $\begin{array}{l}\text { - The knowledge from nurses' } \\
\text { experiences along with the } \\
\text { literature was useful, but was } \\
\text { not sufficient on its own in the } \\
\text { development of practical } \\
\text { solutions for parents. } \\
\text { - Parent's identified larger } \\
\text { systemic issues that needed to } \\
\text { be changed to meet their } \\
\text { needs following this process. }\end{array}$ \\
\hline $\begin{array}{l}\text { Reid-Searl, } \\
200951 \\
\text { QAS: } 330 \\
\text { Happell, } 2009^{50} \\
\text { QAS: } 297.5 \\
\text { Moxham, } \\
\text { 201052 } \\
\text { QAS: } 307.5\end{array}$ & $\begin{array}{l}\text { Explore the } \\
\text { experiences of nurses } \\
\text { who work in a } \\
\text { paediatric unit of a } \\
\text { rural hospital in } \\
\text { Australia using PAR. } \\
\text { Implement \& evaluate } \\
\text { general nurses' } \\
\text { suggestions to } \\
\text { improve health } \\
\text { services. }\end{array}$ & $\begin{array}{l}\text { Diagnostic } \\
\text { - Two focus groups and six interviews were } \\
\text { conducted. } \\
\text { Intervention } \\
\text { - Focus groups explored strategies to } \\
\text { addresses nurses' concerns about mental } \\
\text { health care in a general paediatric unit. } \\
\text { Implementation } \\
\text { - Nurses and local child and adult mental } \\
\text { health service teams implemented } \\
\text { recommendations. } \\
\text { Evaluation } \\
\text { - In phase } 3 \text { action focus groups were } \\
\text { conducted to evaluate phase } 2 \text {. }\end{array}$ & $\begin{array}{l}\text { - Focus groups provide safe } \\
\text { space to share ideas between } \\
\text { participants. Researchers } \\
\text { gained insight into feelings and } \\
\text { beliefs of nursing staff not } \\
\text { identified through interviews. } \\
\text { - Allowed for linear } \\
\text { problem/solution agenda; } \\
\text { used research to facilitate } \\
\text { action. Actions from focus } \\
\text { groups yielded positive } \\
\text { evaluation. }\end{array}$ \\
\hline
\end{tabular}

Continued on next page. 
Table 1: Overview of the Methods Used in the Identified Studies (continued)

\begin{tabular}{|c|c|c|c|}
\hline Citation & Study Aim & Alignment with EBCD Methods & Notable Findings \\
\hline $\begin{array}{l}\text { Day, } 2006^{57} \\
\text { QAS: } 320 \\
\text { Day, } 2011^{56} \\
\text { QAS: } 335\end{array}$ & $\begin{array}{l}\text { Develop a child and } \\
\text { adolescent service } \\
\text { experience (ChASE) } \\
\text { measurement tool in } \\
\text { the UK, involving } \\
\text { youth in South } \\
\text { London. }\end{array}$ & $\begin{array}{l}\text { Diagnostic } \\
\text { - Semi-structured focus groups with youth } \\
\text { followed by a validation group. } \\
\text { Intervention } \\
\text { - } 30 \text { youth developed questionnaire. An } \\
\text { additional } 20 \text { piloted the questionnaire. } \\
\text { Implementation \& Evaluation } \\
\text { - Instrument was piloted by youth. }\end{array}$ & $\begin{array}{l}\text { - Focus groups provided a safe } \\
\text { peer environment. Participants } \\
\text { expressed complex ideas. } \\
\text { - Participative methods } \\
\text { ensured content that was } \\
\text { important to service users. }\end{array}$ \\
\hline $\begin{array}{l}\text { Hildebrand, } \\
2012^{53} \\
\text { QAS: } 270\end{array}$ & $\begin{array}{l}\text { Report on the } \\
\text { development of an } \\
\text { online toolkit using } \\
\text { Action Research to } \\
\text { support small } \\
\text { community mental } \\
\text { health agencies in } \\
\text { Australia. }\end{array}$ & $\begin{array}{l}\text { Diagnostic } \\
\text { - Interviews with agencies and discussion } \\
\text { forums with youth. } \\
\text { Intervention, Implementation \& Evaluation } \\
\text {-16 service reps and } 5 \text { youth developed, trialled, } \\
\text { and improved the online toolkit as necessary. } \\
\text { Feedback mechanisms were included on the } \\
\text { toolkit website }\end{array}$ & $\begin{array}{l}\text { - By including programs in } \\
\text { development, ongoing feedback } \\
\text { improved the usefulness of the } \\
\text { toolkit. } \\
\text { - The toolkit evaluates } \\
\text { programs, measuring } \\
\text { inputs/outputs as well as } \\
\text { activity-based evaluation. }\end{array}$ \\
\hline $\begin{array}{l}\text { L'Etang, } 2012^{54} \\
\text { QAS: } 267.5\end{array}$ & $\begin{array}{l}\text { Develop a Cognitive- } \\
\text { behavioural-based } \\
\text { Counselling } \\
\text { Intervention } \\
\text { Programme (CBCIP) } \\
\text { with youth and } \\
\text { providers using PAR } \\
\text { in South Africa. }\end{array}$ & $\begin{array}{l}\text { Diagnostic } \\
\text { - Open-ended interviews with youth and } \\
\text { service providers assessed needs of youth living } \\
\text { with HIV/AIDS. } \\
\text { Intervention } \\
\text { - Focus groups were held with service } \\
\text { providers to critically examine the content and } \\
\text { process of the CBCIP. } \\
\text { Implementation } \boldsymbol{\&} \text { Evaluation } \\
\text { - A nurse and youth trialed the CBCIP. }\end{array}$ & $\begin{array}{l}\text { - Youth identified needs that } \\
\text { were valuable in the } \\
\text { development of the } \\
\text { intervention. } \\
\text { - The trial indicated concern } \\
\text { with the number of questions } \\
\text { and confusion on some of the } \\
\text { homework. Future research } \\
\text { should engage youth } \\
\text { throughout. }\end{array}$ \\
\hline $\begin{array}{l}\text { Onnela, } 2014^{55} \\
\text { QAS: } 332.5\end{array}$ & $\begin{array}{l}\text { Develop a practice } \\
\text { model with youth, } \\
\text { parents, schoolteachers } \\
\text { and nurses using PAR } \\
\text { for mental health } \\
\text { promotion in a school } \\
\text { in Finland. }\end{array}$ & $\begin{array}{l}\text { Diagnostic } \\
\text { - Initial workshops shared knowledge. } \\
\text { Intervention } \\
\text { - Additional workshops based on the first } \\
\text { workshop. } \\
\text { Implementation \& Evaluation } \\
\text { - Interventions were delivered in schools, } \\
\text { followed by another feedback workshop. }\end{array}$ & $\begin{array}{l}\text { - Engaging various } \\
\text { stakeholders ensures the model } \\
\text { reflects different perspectives. } \\
\text { The PAR process encourages } \\
\text { support and anticipated } \\
\text { cooperation in the } \\
\text { implementation of the model } \\
\text { across sectors. }\end{array}$ \\
\hline $\begin{array}{l}\text { Larkin, } 2015^{5} \\
\text { QAS: } 345\end{array}$ & $\begin{array}{l}\text { Use modified EBCD } \\
\text { with youth, family } \\
\text { members and service } \\
\text { providers to improve } \\
\text { the experience of } \\
\text { hospitalization in } \\
\text { inpatient units in the } \\
\text { UK by translating prior } \\
\text { research findings. }\end{array}$ & $\begin{array}{l}\text { Diagnostic } \\
\text { - Thematic findings from } 3 \text { qualitative studies } \\
\text { that were translated into touch points. } \\
\text { Stakeholder specific feedback groups identified } \\
\text { priorities for change by clustering and ranking } \\
\text { touch points. } \\
\text { Intervention } \\
\text { - A co-design event with all stakeholders began } \\
\text { with films of youth and family to set the tone of } \\
\text { the event. Stakeholders were prepared in } \\
\text { advance and support was available at the event. } \\
\text { Groups worked together to create action plans } \\
\text { to address their identified priority. } \\
\text { Implementation \& Evaluation } \\
\text { - A steering group of staff, users and parents } \\
\text { supported implementation over a } 1 \text {-year period. } \\
\text { Attendance was consistent among a small group } \\
\text { of staff. Audit was conducted at } 9 \text { months. }\end{array}$ & $\begin{array}{l}\text { - The films had a powerful } \\
\text { effect. } \\
\text { - All stakeholders were } \\
\text { respectful of one another and } \\
\text { worked collaboratively. } \\
\text { - Two groups struggled with } \\
\text { their areas. Other working } \\
\text { groups had developed action } \\
\text { plans that addressed these areas. } \\
\text { - There was frustration at the } \\
\text { lack of time and organizational } \\
\text { support to follow through the } \\
\text { plans. } \\
\text { - The audit showed many plans } \\
\text { had minimal progress made. A } \\
\text { number of action plans have } \\
\text { since been executed, but others } \\
\text { remained unimplemented. }\end{array}$ \\
\hline
\end{tabular}

